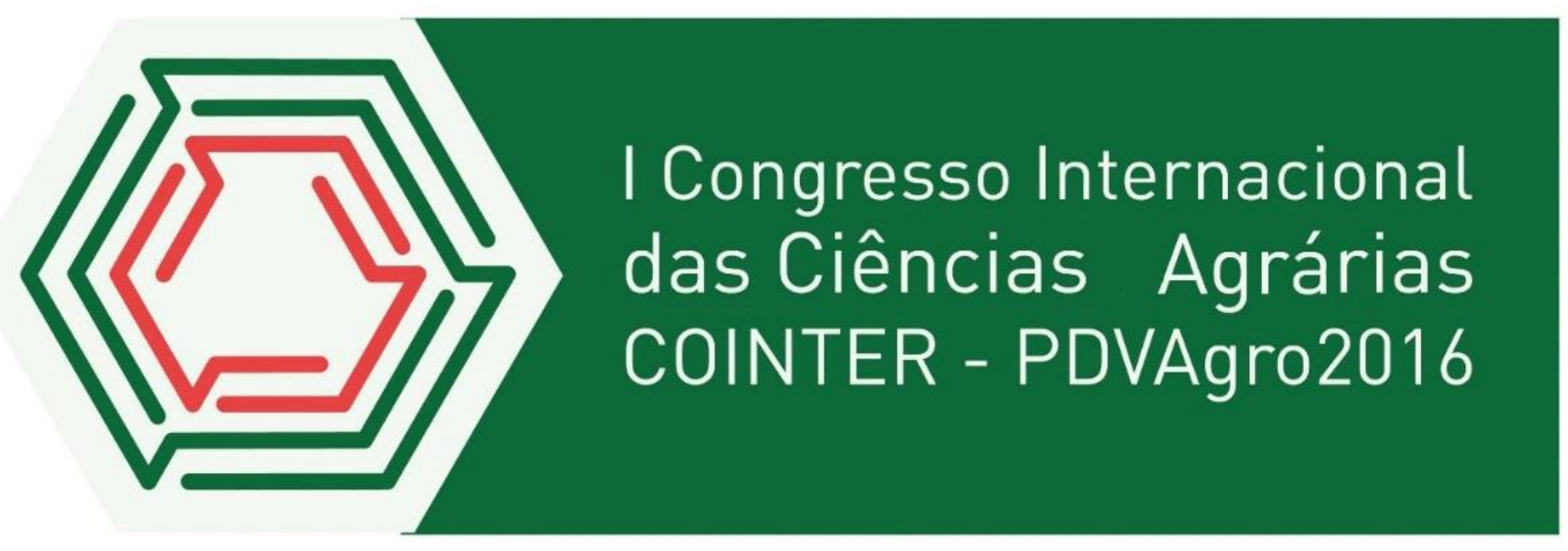

\title{
INDICADORES SOCIAIS E ECONÔMICO DOS PESCADORES ARTESANAIS DA COMUNIDADE VÁRZEA GRANDE, REGIÃO SEMIÁRIDA DA PARAÍBA
}

\author{
Apresentação: Comunicação Oral \\ Sebastiana Joelma de Azevedo Santos ${ }^{1}$; José Wellington de Medeiros Estrela ${ }^{2}$; Cynthia de Lima \\ Campos $^{3}$
}

\begin{abstract}
Resumo
A pescaria é atuante em toda costa brasileira. A atividade pesqueira apresenta relevante importância no modo de vida das famílias envolvidas, portanto, o presente trabalho teve o propósito de descrever os indicadores sociais e econômico dos pescadores artesanais da Comunidade Várzea Grande, região semiárida da Paraíba. A pesquisa foi realizada durante o mês de junho de 2015 com trinta pescadores associados. O universo amostrado foi constituído por 16 homens e 14 mulheres que residem e sobrevivem as margens da barragem Várzea Grande. As entrevistas semiestruturadas foram registradas através de questionários contendo dez questões cada, abordando principais temas como faixa etária, estado civil, nível de escolaridade e renda mensal. A idade dos pescadores variou de 23 a 61 anos, $88 \%$ são casados ou vivem estavelmente com outro companheiro, 67 \% não concluíram o $1^{\circ}$ grau e $77 \%$ tem renda inferior a um salário mínimo. As pescarias realizam-se diariamente e a produção destina-se a intermediários, diretamente a consumidores ou consumo próprio. Os principais problemas enfrentados pelos pescadores relacionam-se a pouca água disponível no reservatório, analfabetismo, baixa renda, conflitos com outros usuários do sistema aquático, poluição e outros fatores climáticos. As políticas públicas para o meio ambiente e desenvolvimento sustentável precisam levar em consideração as demandas e os contextos socioculturais das populações locais em sua diversidade como a necessidade de programas de alfabetização, viabilização para construção de tanque de alvenaria para criação de seus próprios alevinos, cursos profissionalizantes visando agregação de valor ao pescado e fiscalização do manancial no período de despesca.
\end{abstract}

Palavras-chave: escolaridade, faixa etária, pesca artesanal, renda.

\section{Introdução}

\footnotetext{
${ }^{1}$ Pós-graduação em Gestão dos recursos ambientais do semiárido, IFPB/ Campus Picuí, joelmaifpbpicuiy@gmail.com

${ }^{2}$ Graduação em Agroecologia, IFPB/ Campus Picuí, wellingtonestrela18@hotmail.com

${ }^{3}$ Professora do Curso de Agroecologia, IFPB/ Campus Picuí, cynthiazinha1@gmail.com
} 
A barragem várzea grande localizado na Comunidade Várzea Grande possui grande beleza cênica e está localizado apenas $12 \mathrm{~km}$ da sede do município e $254 \mathrm{~km}$ da capital do estado da Paraíba, João Pessoa. Situado no semiárido Nordestino, mais precisamente em uma região de Caatinga, que é propício a longos períodos de estiagem. Este fator climatológico vem afetando seriamente cada vez mais a atividade pesqueira dessa região.

Os pescadores saem para pescar em pequenos grupos, quando a pescaria requer a participação de mais de uma pessoa, ou pescam individualmente nos lugares eventualmente por eles selecionados. Os locais de pesca são escolhidos de acordo com a proximidade de suas residências, além de serem evitados aqueles onde houve pescaria recentemente. Neste caso, há uma rotatividade, para que o ambiente se recupere e seja utilizado novamente.

As populações tradicionais, portadoras de um conhecimento ecológico que regula a reprodução de seu modo de vida, operam suas atividades dentro dos limites impostos pelo ambiente através de sistemas de manejos de recursos marcados pelo respeito aos ciclos naturais e por sua exploração dentro da capacidade de recuperação das espécies utilizadas (DIEGUES, 2004). O uso dos recursos naturais por comunidades locais baseia-se em um conjunto de saberes, práticas e crenças responsáveis pela interpretação do ambiente pelo homem. Esse conjunto de conhecimentos e atitudes constitui o conhecimento ecológico tradicional, o qual está fundamentado nas tradições culturais e na relação íntima com o meio próximo (BERKES, 2009).

O conhecimento local também fornece uma base de informações cruciais para o manejo dos recursos pesqueiros locais, tornando-se necessário, desta maneira, que os recursos explorado pela Comunidade Várzea Grande sejam conhecidos, para que práticas de manejo e ações conservacionistas, baseadas na realidade social na qual os usuários se inserem e não apenas nas características ecológicas do sistema manejado, sejam aplicadas de forma coerente, visando manter a diversidade biológica e cultural.

Com vistas que a atividade pesqueira apresenta uma relevante importância no modo de vida das famílias envolvidas o presente trabalho teve o propósito de descrever os indicadores sociais e econômico dos pescadores artesanais da Comunidade Várzea Grande, região semiárida da Paraíba.

\section{Fundamentação Teórica}

O estado da Paraíba apresenta diversos corpos d'água, disponíveis sobre a forma de rios, lagos, barragens e riachos. Tais ambientes propiciam e favorecem o estabelecimento e manutenção de populações humanas, as quais se utilizam destes ambientes para fins de recreação e desenvolvimento de atividades turísticas e de pesca (CALLIARI et al., 2010), constituindo-se esta última, uma das mais tradicionalmente praticadas. 
As atividades pesqueiras, dependendo de seu objetivo, podem ser divididas nas categorias: subsistência, artesanal e industrial (de média e grande escala). A primeira destina-se ao consumo próprio e/ou familiar, enquanto as demais são comercialmente orientadas (DIEGUES, 2008). As pescarias artesanais são atuantes em toda a costa brasileira e são praticadas por pescadores autônomos, os quais exercem a atividade individualmente ou em parcerias. Estas pescarias empregam apetrechos relativamente simples e o produto é comercializado, normalmente, através de intermediários (DIEGUES, 2009).

Pescarias artesanais fornecem quantidade suficiente de proteína animal para as populações de baixa renda (BAYLEY e PETRERE JUNIOR 2009) e, geralmente, são menos impactantes sobre os recursos pesqueiros do que as industriais, as quais empregam um esforço muito maior (WELCOMME 2005; PAIVA 2007).

Nas pescarias artesanais da região nordeste, os recursos pesqueiros são normalmente explorados através do uso de tarrafas lançadas no meio das águas com o auxilio de canoas não motorizadas. O desenvolvimento da pesca artesanal, principalmente em regiões semiáridas, possui natureza bastante complexa em decorrência da enorme variedade de espécies envolvidas (SILVANO, 2004) e pela variedade de ecossistemas em que é praticada (WORM et al., 2006), como também os fatores climáticos.

Estes ecossistemas proporcionam diferentes benefícios a população, além de estarem diretamente vinculados a vida dos pescadores da região, já que boa parte deles vive nas suas proximidades e deles dependem para a sua sobrevivência (ISSAC et al., 2006; WORM et al., 2006). Entretanto, pressões antrópicas, incluindo a exercida pelas pescarias artesanais (SILVANO, 2004), podem provocar sérios danos ao meio-ambiente, resultando em prejuízos sociais, ambientais e econômicas para essas regiões (WORM et al., 2006).

Muitos pesquisadores têm enfatizado a importância do conhecimento produzido por pescadores artesanais e do seu papel no desenvolvimento e execução de planos de controle e ordenamento da pesca (BEGOSSI, 2006). Desta forma, como o manejo dos recursos naturais está diretamente relacionado ao contexto socioeconômico e político dos seus usuários, é necessário que estes planos levem em consideração as condições locais e a dimensão humana quando da sua elaboração, de maneira a reduzir os conflitos de uso desses recursos (POMEROY, 2005; CLUA et al., 2005).

\section{Metodologia}

O município de Picuí está localizado na mesorregião da Borborema e microrregiões do Curimataú Ocidental e Seridó Oriental Paraibano, é georreferenciado pelas coordenadas geográficas 
de $6^{\circ} 33^{\prime} 18^{\prime \prime}$ de latitude Sul e $36^{\circ} 20^{\prime} 56^{\prime \prime}$ de longitude Oeste, a $426 \mathrm{~m}$ de altitude (IBGE, 2016) e caracterizado, segundo Köppen, como de clima semiárido, tipo Bsh (MENDONÇA, 2007)

A pesquisa foi realizada durante o mês de junho de 2015 com trinta pescadores associados da Colônia de Pescadores na Comunidade Várzea Grande, localizada a 12 km de sua sede, no município de Picuí, estado da Paraíba. O universo amostrado foi constituído por 16 homens e 14 mulheres que residem e sobrevivem ás margens da barragem Várzea Grande.

As entrevistas semiestruturadas foram gravadas quando permitidas pelo entrevistado e registradas através de questionários contendo dez questões cada, abordando principais temas como faixa etária, estado civil, nível de escolaridade e renda mensal. Após a coleta, os dados foram tabulados, utilizando-se procedimentos de análise descritiva, obtendo-se valores da média. Assim também foram obtidos, os valores da frequência relativa percentual, expressa na forma de figuras com os recursos do Microsoft Excel 2010.

\section{Resultados e Discussão}

O perfil socioeconômico dos pescadores estudados foi delineado a partir de questionário semiestruturado. Dos 30 entrevistados, 29 deles residem na comunidade e alguns pertenciam à mesma família e moravam na mesma casa. Apenas 1 deles morava na zona rural do município. Todos os entrevistados possuem casa própria de alvenaria.

Conforme o estado civil, 88 \% são casados oficialmente ou vivem estavelmente com outro companheiro. Enquanto que $6 \%$ são viúvos, mas vivem estavelmente com outro companheiro e $6 \%$ são solteiros.

Quanto à idade dos entrevistados variou de 23 a 61 anos. A faixa etária dos entrevistados oscilou entre 20-29 anos (37\%); 30-39 anos (23\%); 40-50 anos (23\%) e acima de 50 anos (17\%), conforme mostrado na Figura 1.

Figura 1. Faixa etária dos pescadores da Comunidade Várzea Grande. Fonte: Própria. 


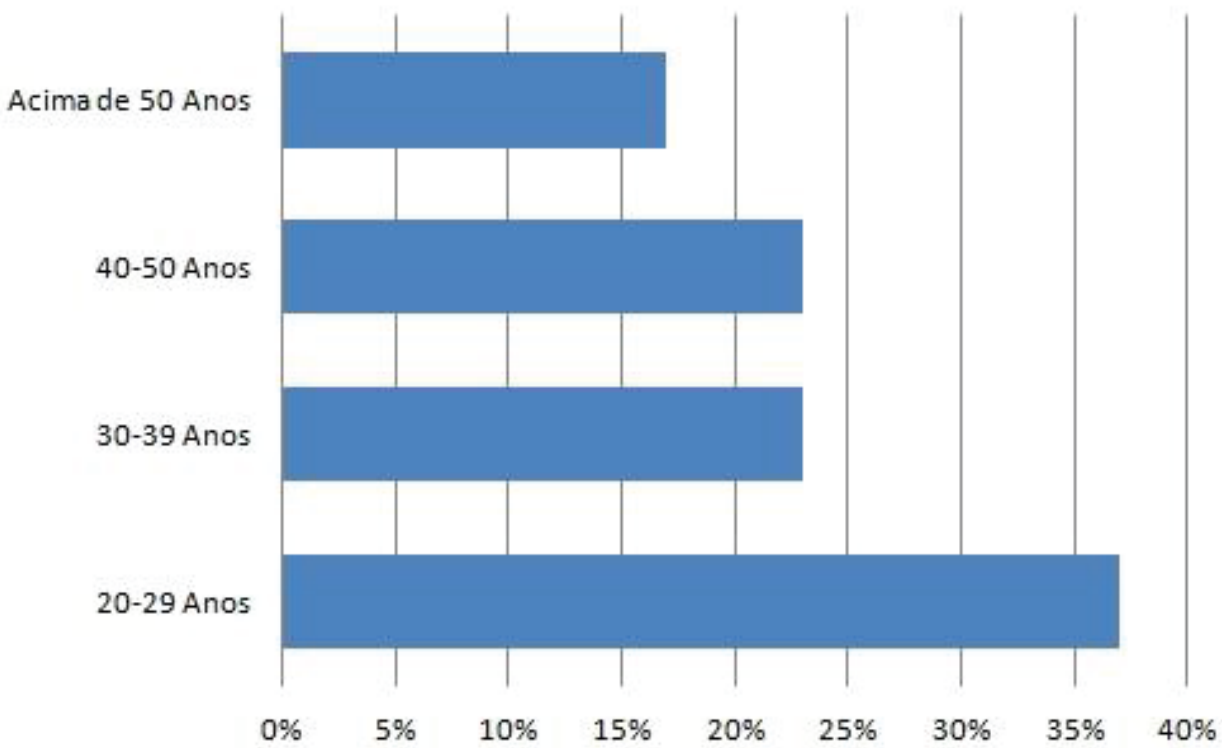

Diante dos resultados expostos observa-se que há uma maior inserção na atividade pesqueira de jovens, sendo esta uma atividade rentável, compreendendo os ensinamentos de geração para geração. Dessa forma, a educação nas famílias deve existir como um projeto educativo que privilegie a participação ativa e consciente (SANTOS E SATO, 2011). A população acima dos 50 anos, está menos envolvido com a atividade devido já estarem próximo a aposentadoria e 3 destes já recebem o benefício.

Em relação ao nível de escolaridade dos entrevistados, $6 \%$ são analfabetos, enquanto que 67 $\%$ possuem o ensino fundamental incompleto, apenas $10 \%$ possuem o ensino fundamental completo e $17 \%$ possuem o ensino médio, representados abaixo na figura 2.

Figura 2. Níveis de escolaridade dos pescadores da comunidade Várzea Grande. Fonte:

Própria.

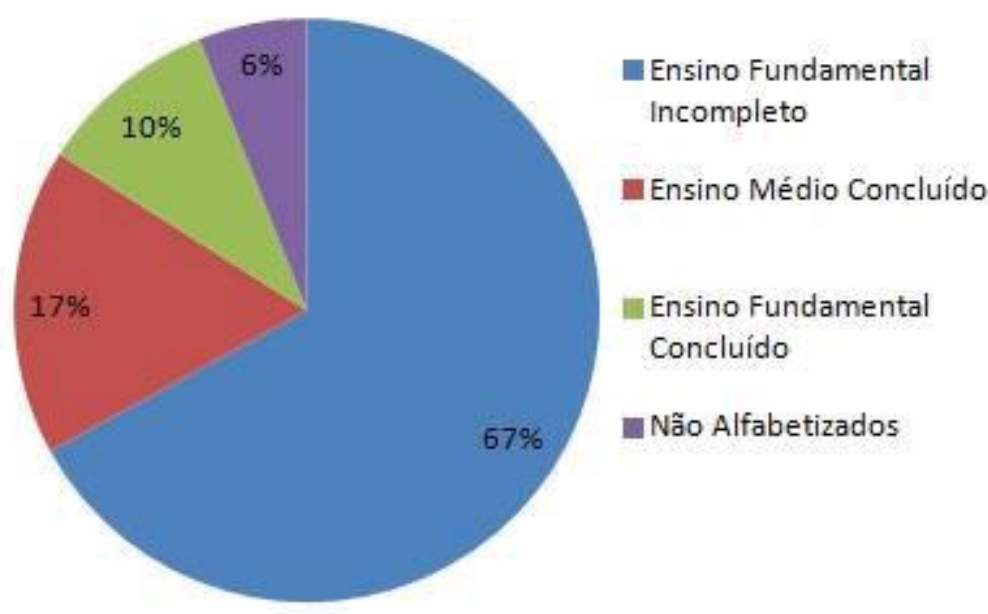


Os baixos níveis de escolaridade demonstrados aqui estão em concordância com o trabalho de Alves e Nishida (2003), que afirmam que o abandono dos estudos e a inserção no mundo do trabalho resultam do contexto social e econômico no qual estas comunidades estão inseridas, onde o sucesso na escola, por membros de seu grupo social, constitui uma exceção.

Para Nishida (2010), a necessidade de contribuir para melhoria da renda familiar e a falta de estímulo para levar adiante os estudos, podem ser apontados como principais fatores para o abandono dos bancos escolares e conseqüentemente para o baixo nível de escolaridade desses pescadores de um modo geral.

Quanto à renda mensal, aqueles que ganham até um salário mínimo, constituem $13 \%$ dos entrevistados, enquanto que $10 \%$ têm renda superior a um salário mínimo. Já $77 \%$ alegam renda inferior a um salário mínimo (Figura 3).

Figura 3. Renda mensal dos pescadores da Comunidade Várzea Grande. Fonte: Própria.

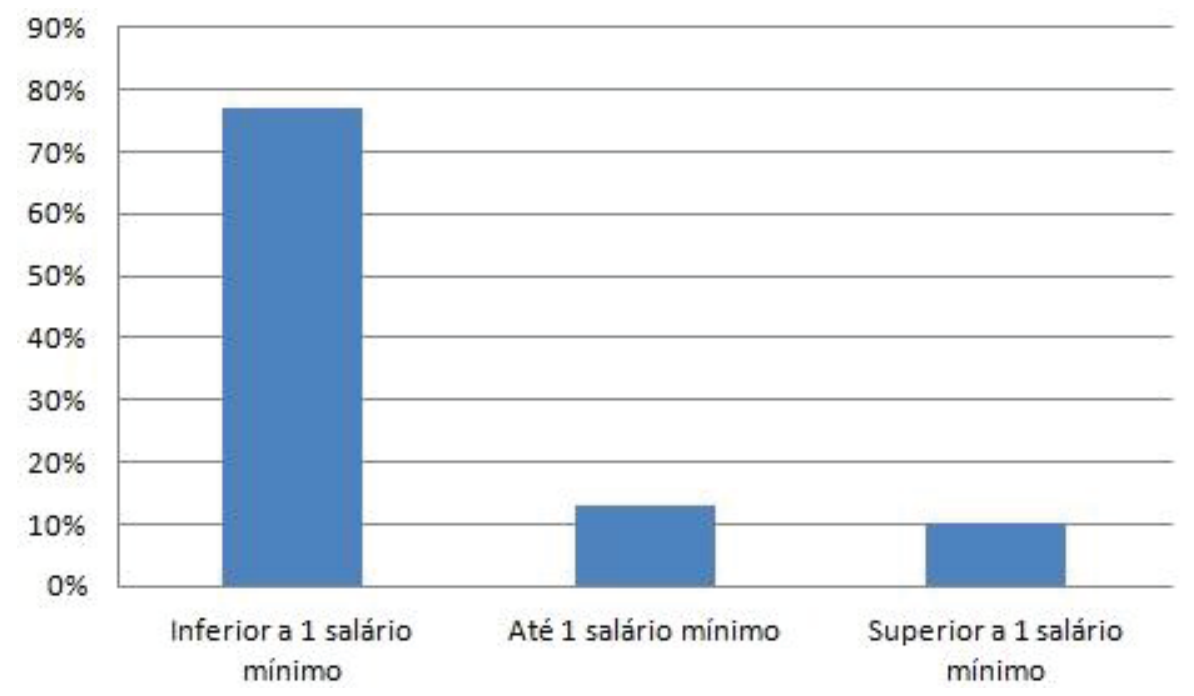

Nesta comunidade, os entrevistados complementam sua renda quando recebem o seguro desemprego no período da desova, que é equivalente a um salário mínimo, recebido anualmente durante três meses e com o Bolsa-Família, para as mulheres. Essas informações corroboram com trabalho realizado na Comunidade Men de Sá- SE por Curado et al, 2009.

Todos os entrevistados possuem carteira de pescador. Isto se deve ao fato de conhecer os benefícios de estar cadastrado em uma colônia.

\section{Conclusões}

Diante dos resultados conclui-se que a renda familiar dos pescadores da Comunidade Várzea Grande obtida com a atividade pesqueira é inferior a um salário mínimo, sendo complementada com auxílio do Programa Bolsa Família e seguro desemprego, no período de desova. 
O nível de escolaridade dos envolvidos é relativamente baixo e a há uma grande quantidade de jovens envolvidos na atividade da pesca artesanal.

A população local carece de políticas públicas para o meio ambiente e desenvolvimento sustentável que levem em consideração as demandas e os contextos socioculturais.

\section{Agradecimentos}

Ao IFPB - Instituto Federal de Educação, Ciência e Tecnologia da Paraíba, Campus Picuí.

Ao NEA - Núcleo de Estudos em Agroecologia.

Ao GPES - Grupo Paraibano de Estudos Socioambientais.

\section{Referências}

ALVES, R. R. N. \& NISHIDA, A. K. Aspectos socioeconômicos e percepção ambiental dos catadores de caranguejo-uçá, Ucides cordatus cordatus (L. 1763) (Decapoda, Brachyura), no estuário do Rio Mamanguape, Nordeste do Brasil. Interciência, v. 28, n. 1, p. 36-43, 2003.

BAYLEY, P. B.; PETRERE JUNIOR, M. 2009. Amazon fisheries: assessment, methods, current status and management options. Can. Spec. Publ. Fish. Aquatic Sci., 106: 385-398.

BEGOSSI, A. (2006). Temporal stability in fishing spots: conservation and co-management in brazilian artisanal coastal fisheries. Ecology and Society, 11(1):5.

BERKES, F. Sacred Ecology: Traditional Ecological Knowledge and Resource Management. Taylor \& Francis. Philadelphia, PA, EEUU. 2009.

CALLIARI, L. et al. 2010. Gerenciamento Costeiro Integrado: trocas e inter-relações entre os sistemas continental e oceânico adjacente. Rio de Janeiro - RJ. FURG, CIRM, DOALOS/ONU. 10 ed.

CLUA, E. et al. (2005). Towards multidisciplinary indicator dashboards for coral reef fisheries management. Aquat. Living Resour., 18:199-213.

CURADO, F.F. et al. Gestão Participativa para o Desenvolvimento Sustentável da Comunidade Ilha Mem de Sá, Itaporanga D’Ajuda, Sergipe. Rev. Bras. de Agroecologia, v. 4, n. 2, p. 2015-2017, 2009.

DIEGUES, A. C. A pesca construindo sociedades. São Paulo: NUPAUB - USP, 315p., 2004.

DIEGUES, A. C. 2008. Pescadores, camponeses e trabalhadores do mar. São Paulo. Editora Ática. Ensaios: 94. 287 p.

DIEGUES, A. C. 2009. A pesca artesanal no litoral brasileiro: cenários e estratégias para sua sobrevivência. Pescadores artesanais - entre o passado e o futuro. FASE, n 38, 74 p. 
IBGE. Instituto Brasileiro de Geografia e Estatística. 2016.

ISSAC, V. J. et al. (2006). A pesca estuarina do Brasil no início do século XXI: recursos, tecnologias, aspectos socioeconômicos e institucionais. Technical report, Universidade Federal do Pará. Belém. 188p.

MENDONÇA, F. Climatologia: noções básicas e climas do Brasil. São Paulo, Oficina de textos, p. 206, 2007.

NISHIDA, A. K.. Catadores de moluscos do litoral Paraibano: estratégias de subsistência e formas e percepção da natureza. 2010. 143f. Tese (Doutoramento em Ecologia e Recursos Naturais). Programa de Pós-Graduação em Ecologia e Recursos Naturais. Universidade Federal de São Carlos, São Carlos, SP, 2010.

PAIVA, M. P. 2007. Recursos pesqueiros estuarinos e marinhos do Brasil. Fortaleza: EUFC, 278p.

POMEROY, R. S. (2005). Community-based and co-management institutions for sustainable coastal fisheries management in southeast. Ocean \& Coastal Management, 27(3):143-162.

SANTOS, J. E.; SATO, M. "Universidade e ambientalismo - encontros não são despedidas". In: Santos, J. E. e Sato, M. (orgs.). A contribuição da Educação Ambiental à esperança de Pandora. São Carlos, Rima, 2011.

SILVANO, R. A. M. (2004). Ecologia de pescadores. Pesca artesanal e etnoictiologia, page 324p. ORG. Begossi, A. São Paulo: Nepam/unicamp: Nupaub/USP: Fapesp.

WELCOMME, R. L. 2005. River fisheries. Fisheries Technical Paper. FAO, Rome, Italy. 330p.

WORM, B. et al. (2006). Impacts of biodiversity loss on ocean ecosystem services science. Ocean \& Coastal Management. 314(5800):787-790. 